\title{
Ensemble bias and variance corrected high-resolution downscaled climate projections for Southeast Asia
}

\author{
J.J. Katzfey ${ }^{a}$, P. Hoffmann ${ }^{\text {a }}$, J.L. McGregor ${ }^{\text {, }}$ K.C. Nguyen ${ }^{a}$ and M. Thatcher ${ }^{\text {a }}$ \\ ${ }^{a}$ CSIRO Marine and Atmospheric Research, Aspendale, VIC \\ Email: Jack.Katzfey@csiro.au
}

\begin{abstract}
Due to its complex topography and diverse climate (e.g. monsoonal rainfall, tropical cyclones), Vietnam is expected to be greatly affected by climate change. Therefore, detailed information about possible changes is crucial for the planning of climate adaptation measures. The most recent climate projections generated by coupled global climate models (GCMs) as well as earth system models (ESMs) for the CMIP5 experiment are still too coarse to provide this information. Using the conformal-cubic atmospheric model (CCAM), a stretched-grid atmospheric model, regional climate projections with approximately $10 \mathrm{~km}$ horizontal resolution over Vietnam have been produced. The downscaling method involves two steps. First, a global $50 \mathrm{~km}$ even-grid run is conducted driven just by bias and variance corrected monthly sea surface temperatures and sea ice concentrations from six different CMIP5 GCMs/ESMs and two RCP emission scenarios (RCP4.5 and RCP8.5). In the second step of the downscaling method, a $10 \mathrm{~km}$ stretched-grid version of CCAM is forced by spectrally filtered results from the $50 \mathrm{~km}$ global simulations.

Validation of the $50 \mathrm{~km}$ and the $10 \mathrm{~km}$ simulations of the present climate will be presented. The climate projections from the GCMs, $50 \mathrm{~km}$ and $10 \mathrm{~km}$ simulations will also be discussed to show some of the impact of the downscaling method and resolution on the projections for Southeast Asia and Vietnam.
\end{abstract}

Keywords: Climate change, regional climate, dynamical downscaling, Vietnam 
Katzfey et al., Ensemble bias and variance corrected high-resolution downscaled climate projections for Southeast Asia

\section{INTRODUCTION}

The High-resolution Climate Projections for Vietnam (HCPV) is a project funded by Australia's Agency for International Development (AusAID) in part to support Vietnam in its efforts to update their national Climate Change and Sea Level Rise Scenarios by 2015. This update is required to incorporate new climate science information released by the Inter-governmental Panel on Climate Change and to provide more detailed projections at a regional level. This project is delivered through a partnership between the Commonwealth Scientific and Industrial Research Organisation (CSIRO), IMHEN and the Hanoi University of Science (HUS).

Building on the latest available climate information, this project presents a range of possible climate futures over seven climatic regions of Vietnam, with the following advancements:

- New emission scenarios: lower (RCP 4.5) and higher (RCP 8.5) scenarios were used for the regional modelling, while four scenarios were used for sea-level rise (RCP 2.5, 6.5, 4.5 and 8.5)

- Improved global information: six of the latest global climate models were used

- New approach to regional projections: sea surface temperature errors in global projections were corrected, new global climate projections were produced, then detailed projections (10-20 km resolution) over Vietnam were generated

- Multi-model assessment: results from multiple regional and global models were synthesised and analysed.

\section{CLIMATE CHANGE TRENDS FOR CURRENT CLIMATE 1971-2010}

The key trends in current observations for temperature and rainfall determined through analysis of highquality observed station data are given below. Data from 70 stations were used across Vietnam.

Temperature has been increasing by $0.15^{\circ} \mathrm{C}$ to $0.35^{\circ} \mathrm{C}$ per decade over the past 40 years (Figure 1 , left). The warming is less in the coastal stations than in inland stations. Warming is greater in winter months than in summer, and the southern regions are warming faster than the northern regions. Note that Vietnam's average temperature is increasing at approximately twice the rate of global warming over the same period Nguyen et.al. (2013).

Temperature

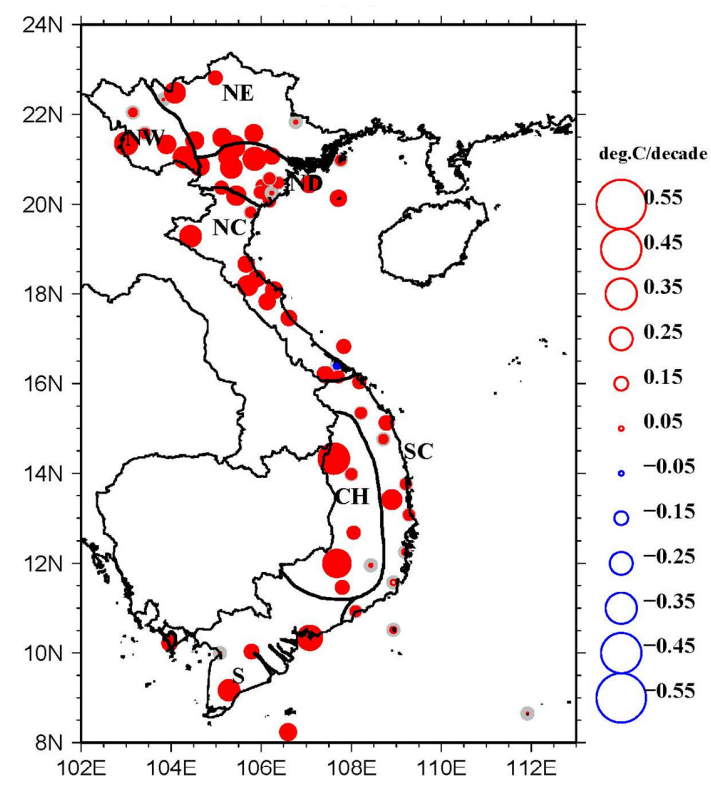

Rainfall

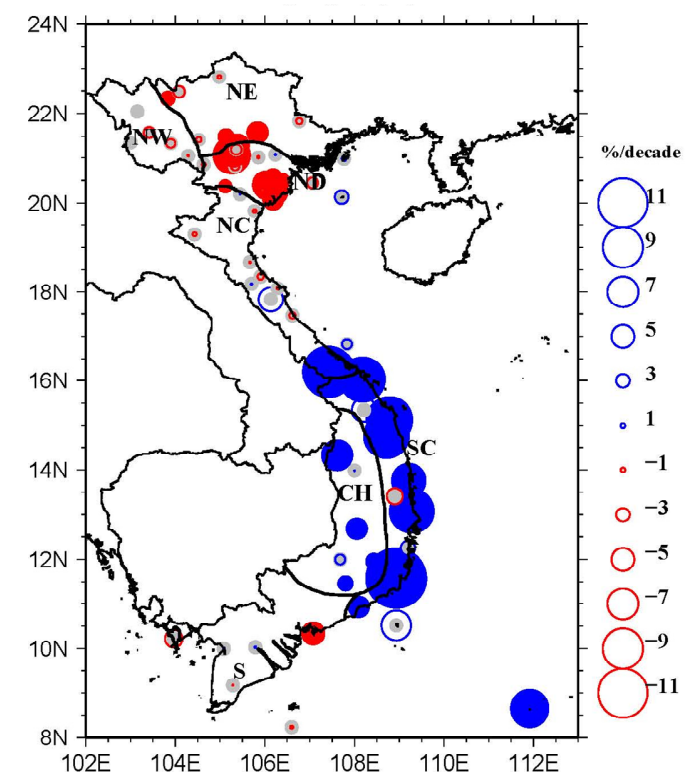

Figure 1: Mean annual temperature (left) and rainfall (right) trends from 1971 to 2010. Trends in temperature are shows as ${ }^{\circ} \mathrm{C}$ per decade. Trends in rainfall are shown as percentage per decade. Solid fill of circles indicates statistical significance at the $90 \%$ confidence level.

Annual rainfall (Figure 1, left) has been increasing in most of the coastal regions of south central Vietnam by around $10 \%$ per decade, and decreasing in the northern regions by around $5 \%$ per decade. 
Katzfey et al., Ensemble bias and variance corrected high-resolution downscaled climate projections for Southeast Asia

\section{CLIMATE MODELING METHODS}

\subsection{Emissions Scenarios}

The latest emissions scenarios (Representational Concentration Pathways) being developed for the International Panel on Climate Change's 5th Assessment Report are based upon a new set of possible carbon (CO2) concentrations. These are different compared to the previous Special Report on Emissions Scenario (SRES) IPCC (2000) options used in the 4th Assessment Report IPCC (2007), with updated assumptions of technological and industrial growth. Due to the limited time and computing resources available to this project, only two emissions scenarios (RCP 4.5, with lower concentrations and RCP 8.5, with higher levels of CO2) have been incorporated, while for sea-level rise projections, which are less computer intensive, four scenarios were used (RCP 2.5, 6.5, 4.5 and 8.5).

\subsection{From Global to Regional Projections}

For regions such as Vietnam, the horizontal resolution of Global Climate Models (GCMs), generally limited to $100-200 \mathrm{~km}$, is too coarse to capture the coastal and terrain effects on temperature, rainfall and other features of local climate, as well as the frequency of extreme events such as tropical cyclones. Therefore, in this project the results from global models are downscaled by Regional Climate Models (RCMs). These RCMs simulate the atmosphere and the land surface for a smaller region, but use the large-scale information (ocean temperatures and sea ice) from global models.. This process, known as dynamical downscaling, allows projection of future changes in local climate in much more detail (10-20 km resolution) without exhausting computing resources. In this study, six GCMs were chosen to downscale. They were chosen based upon a range of performance criteria for the current climate and for their varying patterns of projected climate change, to address the inherent uncertainty of future projections and capture the full range of possibilities.

Before using in the RCMs, the monthly sea surface temperature (SST) data from the global models selected were corrected for their biases and their differences in interannual variability. First, the variance of the SSTs was corrected using a multiplier factor, then the bias was subtracted. This procedure, applied to all months of the GCM, will give climatological mean SSTs that match the observed climatology, and interannual variability that matches the observed variability. The frequency of the interannual variation in SSTs is still determined by the source GCM, as is the climate change signals.

The downscaling procedure, summarized in Figure 2, uses the corrected monthly GCM SSTs and sea ice concentrations as inputs to the Conformal-Cubic Atmospheric Model (CCAM) developed at CSIRO, which was then run at a global resolution of $50 \mathrm{~km}$. Concentrations of greenhouse gases and aerosols were specified from the selected RCP. These results were then used to further downscale using a stretched-grid version of CCAM with resolution over Vietnam of $10 \mathrm{~km}$. The large-scale information from the $50 \mathrm{~km}$ simulations was imposed using a spectral filter approach Thatcher and McGregor (2009).

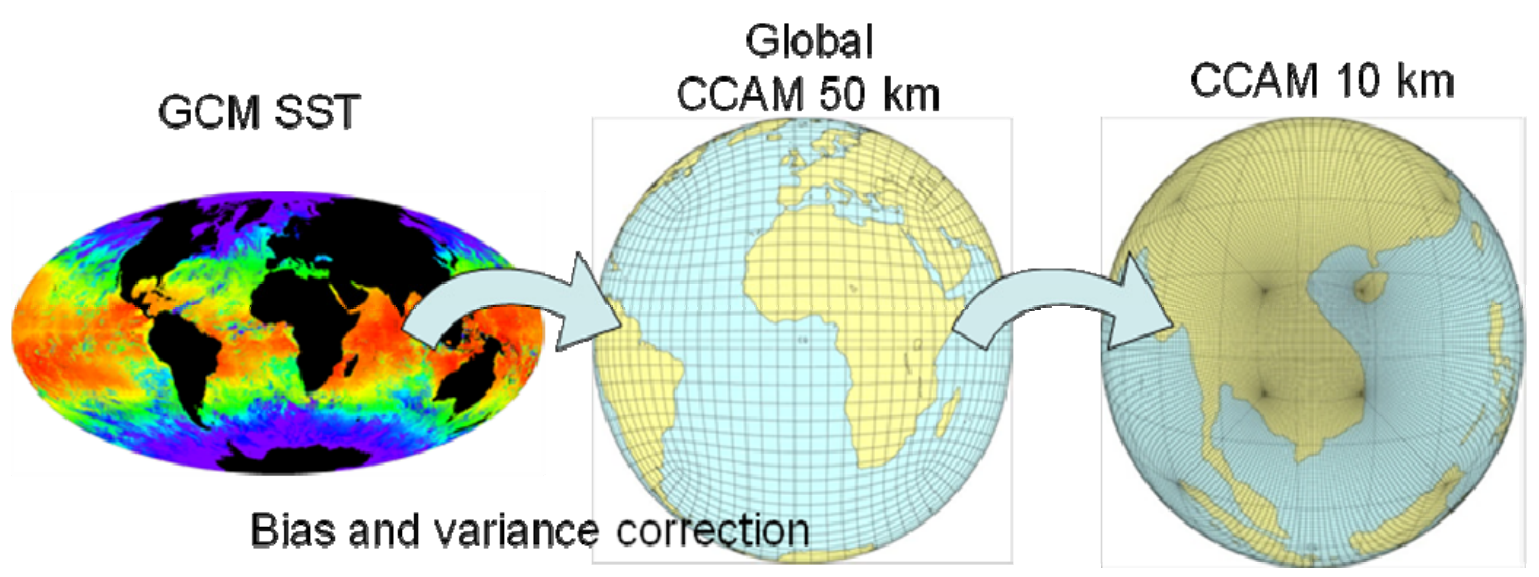

Figure 2. Downscaling procedure. See text for details.

An additional set of downscaled simulations was performed in a slightly different manner using the regional model RegCM4 at $20 \mathrm{~km}$ resolution. In this case, a $100 \mathrm{~km}$ global version of CCAM was used to generate the lateral boundary conditions for RegCM4. In addition, only time-slice experiments were conducted. A 
Katzfey et al., Ensemble bias and variance corrected high-resolution downscaled climate projections for Southeast Asia

An additional set of downscaled simulations was performed in a slightly different manner using the regional model $\mathrm{RegCM} 4$ at $20 \mathrm{~km}$ resolution. In this case, a $100 \mathrm{~km}$ global version of CCAM was used to generate the lateral boundary conditions for RegCM4. In addition, only time-slice experiments were conducted. A summary of the various model runs completed is given in Table 1.

\begin{tabular}{|c|c|c|c|c|}
\hline Model & $\begin{array}{l}\text { Resolution/ } \\
\text { vertical levels }\end{array}$ & $\begin{array}{l}\text { GCM data } \\
\text { used }\end{array}$ & Input data & $\begin{array}{l}\text { Times } \\
\text { simulated }\end{array}$ \\
\hline CCAM & $\begin{array}{l}50 \mathrm{~km} / 27 \\
100 \mathrm{~km} / 18\end{array}$ & $\begin{array}{l}\text { CNRM-CM5, } \\
\text { CCSM4, } \\
\text { ACCESS1.0, } \\
\text { NorESM1-M, } \\
\text { MPI-ESM-LR, } \\
\text { GFDL-CM3 }\end{array}$ & $\begin{array}{l}\text { Variance and } \\
\text { bias corrected } \\
\text { SSTs and sea ice } \\
\text { concentrations }\end{array}$ & 1970-2099 \\
\hline CCAM & $10 \mathrm{~km} / 27$ & $\begin{array}{l}\text { CNRM-CM5, } \\
\text { CCSM4, } \\
\text { ACCESS1.0, } \\
\text { NorESM1-M, } \\
\text { MPI-ESM-LR, } \\
\text { GFDL-CM3 } \\
\end{array}$ & CCAM $50 \mathrm{~km}$ & 1970-2099 \\
\hline RegCM4 & $20 \mathrm{~km} / 19$ & $\begin{array}{l}\text { ACCESS1.0, } \\
\text { NorESM1-M }\end{array}$ & CCAM $100 \mathrm{~km}$ & $\begin{array}{l}1980-2000 \\
2045-2065 \\
2080-2099\end{array}$ \\
\hline
\end{tabular}

\section{CLIMATE CHANGE AT THE END OF THE 21ST CENTURY UNDER RCP 8.5}

A summary of the projected changes in climate across Vietnam by the end of the 21st century under RCP 8.5 is presented here.

\subsection{Temperature Increases}

New detailed projections show annual temperature increases, largest in the north. Temperatures across the seven regions are projected to increase by $2.2^{\circ} \mathrm{C}$ to $6.1^{\circ} \mathrm{C}$ by the end of the 21 st century. A consequence of this warming is a greater number of hot days (above $35^{\circ} \mathrm{C}$ ) and heatwaves (more than five consecutive days of extreme temperatures). These results are consistent with the already observed warming at stations across Vietnam. All model simulations agree that there will be warming, but disagree somewhat on the amount. The largest projected increase could have serious consequences for agriculture and other human activities.

\subsection{Seasonal and Regional Rainfall Changes}

Annual rainfall changes across Vietnam are projected to range between $-30 \%$ and $+60 \%$ by the end of the 21 st century. Summer rainfall is projected to decrease for large parts of Vietnam. In central Vietnam, rainfall is projected to increase for all other seasons (see Figure 3). However, there is little agreement among models on the amount and direction of the change. The frequency of agricultural droughts is projected to increase, and extreme rainfall amounts are projected to increase, except in central Vietnam. These changes, particularly the upper and lower values, coupled with the effects of temperature increases, could have large impacts on agriculture and water resources. Due to the lack of agreement among models, a range of possible changes should be considered in planning decisions. 
Katzfey et al., Ensemble bias and variance corrected high-resolution downscaled climate projections for Southeast Asia
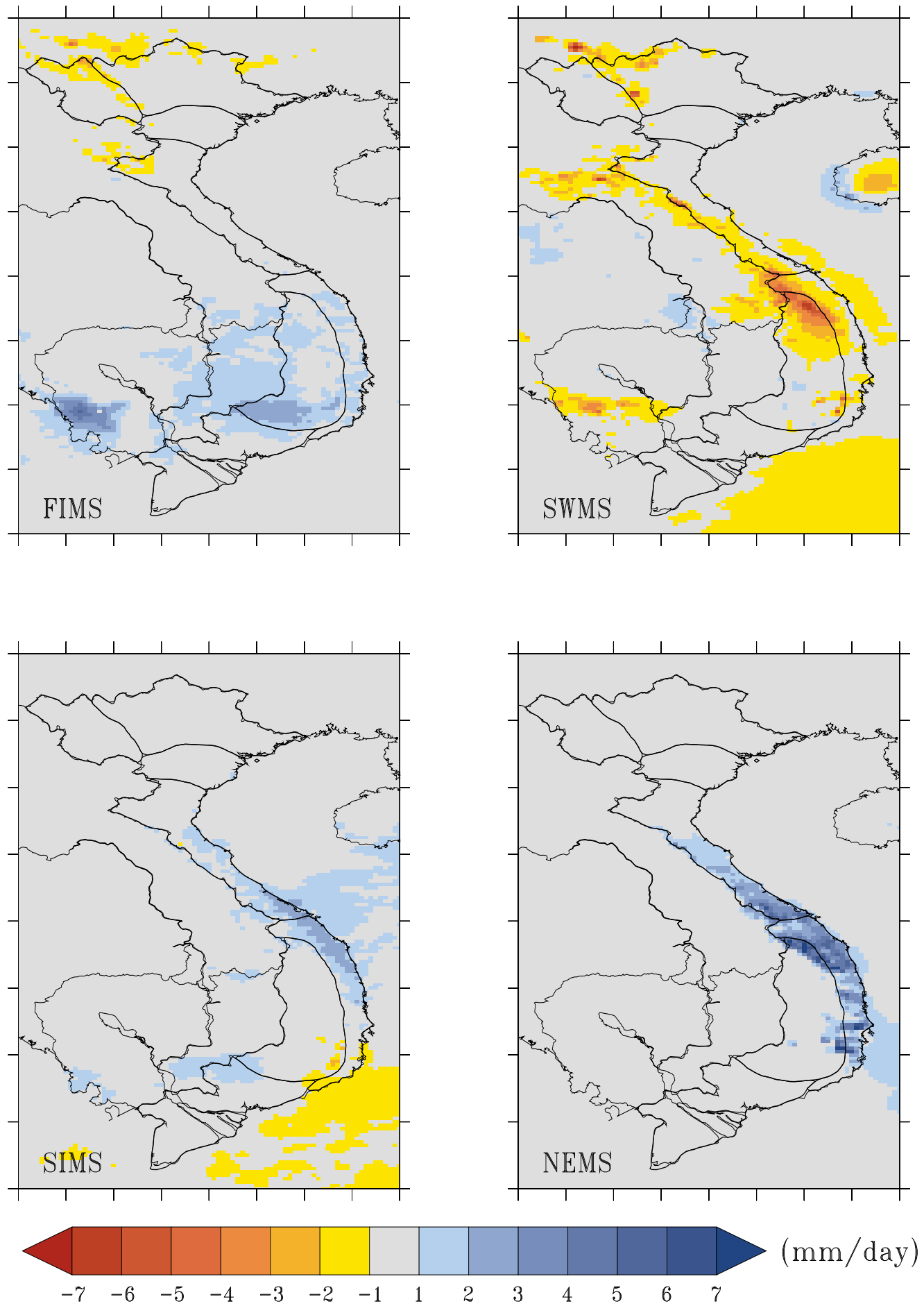

Figure. 3: RCM multi-model mean seasonal rainfall change (mm/day) by 2080-2099 relative to 1980-2000 using RCP 8.5. FIMS is the First Inter-Monsoon Season (April-May), SWMS is the South West Monsoon Season (June-September), SIMS is the Second Inter-Monsoon Season (October-November) and NEMS is the North East Monsoon Season (December-March).

\subsection{Fewer, but Possibly More Intense, Tropical Cyclones}

The preliminary analysis of the projections from this research and other studies shows a decrease in the number of tropical cyclones. Other studies have indicated that their intensity may increase. The complexity of the factors that influence the formation of tropical cyclones makes them hard to predict; thus further investigation is required to determine their potential future impact on Vietnam. 
Katzfey et al., Ensemble bias and variance corrected high-resolution downscaled climate projections for Southeast Asia

\section{RECOMMENDATIONS FOR THE USE OF CLIMATE PROJECTIONS}

As mentioned in the explanation of projections, the future climate will be determined by a combination of factors, including levels of greenhouse gas emissions, unexpected events (e.g. volcanic eruptions), changes in technology and energy use, as well as natural variability. Exactly how these factors will unfold is still unknown, so a range of potential changes should be considered to ensure that known risks and impacts are captured in planning and project design. This research has used two greenhouse gas scenarios, taken information from a range of global climate models, and developed projections from multiple high-resolution (detailed) models to ensure that a broad range of plausible changes have been evaluated.

This research has revealed some new insights into the potential future climate in Vietnam, given our current understanding. In assessing the impact of these projections, a range of possible futures should be considered and careful analysis is required. For example, while the results suggest little change in annual rainfall, the projected decrease in rainfall during the summer monsoon season may have significant hydrological implications, which could impact areas such as water resource planning and agriculture. This may potentially be made worse by the projected increase in the frequency of droughts and the more intense extreme rainfall. Users should collaborate with climate experts and other advisors to identify the best means for applying these new findings in their planning processes and in future project design.

An example of how the new climate change projections can provide evidence for climate adaptation planning is the proposed AusAID funded Ca Mau project, which will be part of the Climate Change and Coastal Ecosystems Program. This project will carefully assess key climate information against external factors, such as social structures, economic circumstances and other environmental issues, to inform Ca Mau's provincial climate action plan. An integrated assessment approach will be applied to ensure that decisions are most beneficial to a range of areas.

\section{CONCLUSIONS}

New high-resolution climate projections have been produced for Vietnam based upon the latest GCM data available from CMIP5. Key highlights of these projections are the potential decrease in summer rainfall, increase in extreme rainfall amounts and longer droughts, all of which could have significant impact on agriculture and water resources in Vietnam. The project has generated a broad range of detailed, regionally specific evidence of warming and other changes in the future climate of Vietnam. Only some key research findings and recommendations are provided here, along guidance on their use. Further detail is available in the Summary Document, Technical Report and Regional Summaries available on the project website (www.vnclimate.com.vn). The results presented from this research are only the first step in developing a greater understanding of future climate. Further research is needed to fully understand the drivers behind projected changes, in particular the causes of changes in rainfall and how this affects monsoon, tropical cyclones and drought.

Climate models are continually developing, which will lead to improved climate projections. In addition, understanding of and confidence in climate projections will increase as research continues. Users should ensure any climate projections they are working with are updated every two to three years.

\section{ACKNOWLEDGMENTS}

The High-resolution Climate Projections for Vietnam is a project funded by the Australian Agency for International Development (AusAID).

\section{REFERENCES}

Nguyen, D.-Q., Renwick, J. and McGregor, J., (2013). Variations of surface temperature and rainfall in Vietnam from 1971 to 2010. International Journal of Climatology, doi: 10.1002/joc.3684.

IPCC SRES, (2000). In Nakićenović, N., and Swart, R., Special Report on Emissions Scenarios: A special report of Working Group III of the Intergovernmental Panel on Climate Change, Cambridge University Press, ISBN 0-521-80081-1, 978-052180081-5 (pb: 0-521-80493-0, 978-052180493-6).

IPCC, (2007). Climate Change 2007. Impacts, Adaptation, and Vulnerability. Contribution of Working Group II to the Fourth Assessment Report of the Intergovernmental Panel of Climate Change, Cambridge University Press.

Thatcher, M., and J. L. McGregor, (2009). Using a scale-selective filter for dynamical downscaling with the conformal cubic atmospheric model. Monthly Weather Review, 137: 1742-1752. 